\title{
UMA ANÁLISE DE REDE DAS MÍDIAS TRADICIONAIS E A COBERTURA DAS ELEIÇÕES DE 2018
}

\author{
Virgílio De Araújo Mendes ${ }^{1}$ \\ Renan Barbosa Diniz ${ }^{2}$
}

\section{Resumo:}

O presente artigo visa discutir como alguns veículos de mídia impressa realizaram a cobertura da eleição presidencial brasileira de 2018. As mídias jornalísticas constituem um aspecto importante para a construção da opinião pública em uma democracia e, também, cumprem papel de agentes de distribuição do fluxo informacional. Assim, este trabalho apresenta estatísticas descritivas sobre a proporção da presença de cada candidato nas capas de mídia impressa, a fim de contribuir para a literatura dedicada ao estudo mídia e eleições, além de tentar responder à pergunta se houve ou não viés na cobertura da eleição presidencial brasileira de 2018. Para além disso, utilizamos também o método de Análise de Redes Sociais (ARS) como ferramenta analítica no intuito de identificar as redes de relacionamento dos atores políticos presentes nas capas coletadas. Nossos resultados apontam para dois momentos diferentes das eleições, ambos com tempo de exposição desigual dos candidatos. Um antes da facada sofrida por Bolsonaro, quando Lula era o personagem mais citado. E outro posterior à facada, quando Bolsonaro teve presença majoritária nas mídias estudadas.

Palavras-chave: mídia impressa; eleições presidenciais; Análise de Rede Social;

\section{A network analysis of the traditional media coverage during the 2018 elections}

\begin{abstract}
:
This paper aims to discuss how some print media vehicles covered the presidential electoral processes of 2018 in Brazil. The news media constitute an important aspect for public opinion in a democratic regime and in the information distribution flow. This work presents some descriptive statistics about the proportion each candidate appeared on the cover of the print media studied, so we can contribute to the literature dedicated to media and elections and try to answer if there was or not a bias in the coverage of the Brazilian presidential election of 2018. Beyond that, we utilize the Social Network Analysis (SNA) as a tool to identify the relationship networks between the political actors present on the covers collected. Our results point to two different moments on the elections and in which we found, in both, an uneven media exposure of the candidates. First, the period before the attempt of murder suffered by Bolsonaro, when Lula was the most mentioned character. Second, a period after the stabbing, when Bolsonaro was the prevailing figure in the media studied.
\end{abstract}

Keywords: print media; presidential elections; Social Network Analysis;

1 Mestrando em Ciência Política na UFMG, pesquisador nas áreas de comportamento político e mídias digitais, e Bacharel em Ciências Sociais pela Universidade Federal de Minas Gerais (UFMG). Ex-diretor da Coordenadoria de Projetos da MEIOS - Empresa Júnior de Ciências Sociais da UFMG e ex-Data Analyst na Quaest Consultoria e Pesquisa com experiências em processamento e análise de dados de survey. Lattes: http://lattes.cnpq.br/3781647781988333; Linkedin: https://www.linkedin.com/in/virgiliomendes/. Contato: virgilioebm@gmail.com 2 Graduando em Ciências Sociais na UFMG, pesquisador das áreas de mídia, eleições, comportamento político e opinião pública. Ex-bolsista Fapemig no projeto de pesquisa Media Bias. Linkeln: https://www.linkedin.com/in/renanbarbosadiniz/. Contato: renanbarbosadiniz@gmail.com 


\section{Introdução}

Desde o primeiro processo eleitoral brasileiro no período pósredemocratização, em 1989, a mídia tem desempenhado um papel central tanto na cobertura das eleições, como na formação da opinião pública em relação aos candidatos. A literatura dedicada ao estudo da cobertura realizada pela mídia durante períodos eleitorais aponta para a existência de viés dos principais veículos de mídia brasileira já na cobertura de seu primeiro processo eleitoral, como mostram Kucinsky (1998) e Lins da Silva (1990). Apesar de haver discordância entre os autores acerca do impacto real que este viés é capaz de produzir nos resultados do pleito, há pouca divergência quanto à existência de uma cobertura enviesada, que privilegiaria um dos lados em detrimento dos outros. Nós compartilhamos da opinião de que a cobertura da mídia desempenha um importante papel na formação da opinião pública e, por consequência, na decisão de voto dos eleitores (BEZERRA e MUNDIM, 2011; FIGUEIREDO, 1998; LOURENÇO, 2003; MIGUEL, 2003; MUNDIM, 2010, 2018).

Mesmo que a existência de viés na cobertura midiática das eleições brasileiras seja ponto pacífico, faz-se necessário que novos estudos sejam realizados na medida em que novas eleições forem ocorrendo. Os ciclos eleitorais costumam mesclar elementos de continuidade das eleições anteriores com fatores novos que não existiam em eleições passadas. Por isso, mesmo já existindo trabalhos demonstrando o viés na cobertura midiática do processo eleitoral, estudos dessa natureza são importantes a cada nova eleição para averiguar o balanço do que sobreviveu à prova do tempo e quais novos fatores passaram a fazer parte do processo eleitoral e de sua cobertura. Contribuindo assim, não apenas academicamente, mas também com o exercício pleno da democracia brasileira, uma vez que a cobertura midiática tem poder de influência sobre a opinião pública e, dessa maneira, pode alterar os destinos políticos do país favorecendo ou prejudicando esse ou aquele candidato, o que diminui a credibilidade do processo eleitoral como um todo e, por sua vez, enfraquece a própria democracia.

Esse viés pode se expressar de duas maneiras diferentes: através da publicação de matérias nas quais é utilizado um tom editorial não neutro, ou seja, contar um fato jornalístico de maneira a enfatizar aspectos positivos ou negativos relacionados à matéria. Esse fenômeno é de natureza qualitativa e diz respeito a como a 
matéria é enquadrada, de maneira que a escolhas editoriais ditem um tom que influencie a percepção de quem a lê. Existem estudos que se propõem a estudar a valência da cobertura midiática em período de eleições, a fim de explorar se há ou não viés e a quem ele favorece, como Feres Júnior e Sassara (2016). Porém, esta não foi a metodologia empregada neste artigo. A outra maneira pela qual o viés midiático pode ser percebido, é através da exposição desproporcional dos candidatos, ou seja, o espaço concedido para cada candidato na mídia é desigual (FIGUEIREDO, 1998; MUNDIM, 2018). Teoricamente, todos os candidatos deveriam ter oportunidades iguais de exposição midiática a fim de assegurar o princípio da imparcialidade no exercício da cobertura. Este artigo busca fornecer elementos que possibilitem responder se houve viés na cobertura do processo eleitoral de 2018, a partir da contabilização de aparições dos candidatos nas capas dos principais veículos de mídia impressa diária nacional. É importante ressaltar que, por si só, nenhuma dessas dimensões é suficiente para a confirmação categórica da existência de viés, porém, ambas são componentes importantes na busca por responder sobre a existência de viés. Portanto, trazemos nesse artigo um balanço do espaço concedido pelos veículos de mídia estudados, o que nos fornece elementos para começar uma discussão sobre como foi a cobertura nas mídias impressas coletadas e analisadas.

Partimos da hipótese que há viés por parte da mídia nacional ao realizar a cobertura das corridas eleitorais, como a literatura nos sugere que tem acontecido historicamente nos últimos processos eleitorais (ALDÉ, 2003; ALDÉ, MENDES e FIGUEIREDO 2007; FIGUEIREDO, 1998; LOURENÇO, 2009; BEZERRA e MUNDIM, 2011). O que os dados nos mostram é que, como sugerido pela literatura existente sobre o tema, a mídia distribuiu a exposição dos candidatos de maneira desigual, dando indícios de confirmação da existência de viés no tempo de exposição. Isso fica mais evidente no período compreendido entre o primeiro e segundo turno, quando havia apenas dois candidatos na disputa. Na semana depois do primeiro turno, Jair Bolsonaro, candidato pelo PSL (Partido Social Liberal), esteve presente em $48,4 \%$ das capas levantadas, enquanto Fernando Haddad, candidato pelo PT (Partido dos Trabalhadores), apareceu em $30,6 \%$ delas. Na semana seguinte, uma antes do segundo turno, Bolsonaro apareceu em $58,1 \%$ das notícias de política, enquanto Haddad foi citado em apenas $34,3 \%$ delas, como o primeiro gráfico da seção três nos mostra. Isso corrobora também com a tese de defendida por Feres Júnior e Sassara (2016), que mostra o viés antipetista por parte da mídia brasileira. 
Quanto a cobertura de outros candidatos que se apresentavam como sérios candidatos à presidência, como Ciro Gomes do PDT (Partido Democrático Trabalhista) e Geraldo Alckmin do PSDB (Partido da Social Democracia Brasileira), observamos que ambos foram coadjuvantes aos olhos da mídia durante a maior parte do processo eleitoral, sendo que Ciro não foi o mais citado em nenhuma das semanas, já Alckmin apareceu mais vezes que seus adversários nas semanas 29 e 30 , quando teve $33,8 \%$ e $44,1 \%$ do número de citações respectivamente.

Apesar de seu valor heurístico indiscutível, é necessário reconhecer a limitação encontrada pela escolha metodológica deste artigo e estressar o fato de que tempo de exposição não dá conta de analisar como a cobertura é feita, em outras palavras, muito tempo de exposição positiva pode acarretar diferentes impactos do que muito tempo de exposição negativa teria. Como citado anteriormente, para que essa dimensão da cobertura seja contemplada na análise, é recomendável a produção de outros estudos mais focados nesse aspecto qualitativo, seja utilizando-se da metodologia de análise de valência ou outras metodologias. Dessa maneira, ao se associar os aspectos quantitativos e qualitativos, passa a ser possível elaborar uma resposta mais robusta sobre a existência de viés durante a cobertura das eleições nas mídias estudadas.

Na segunda parte, ainda na terceira seção, os mesmos dados foram utilizados para a elaboração de um grafo de redes contendo os atores políticos e veículos de mídia presentes nas capas e as relações entre eles. A intenção ao incorporar esse recurso ao nosso trabalho era mapear e dimensionar a rede de atores políticos e institucionais a partir da metodologia de Análise de Redes Sociais (ARS). Para o grafo de redes, ao contrário do gráfico de porcentagem de citações, não é possivel identificar a proporção de citações de cada candidato numericamente, entretanto, é possível se ter uma ideia sobre o volume de citações de cada um dos veículos de mídia estudados por esse artigo, já que a espessura da conexão entre os nós, que representa esse volume, é proporcional ao número de citações, portanto, quanto mais citado for um candidato por aquele veículo, mais grossa será a linha que conecta os dois na rede observada. Com isso em mente, podemos constatar, por exemplo, que Bolsonaro foi o mais citado de todos os candidatos, como já havíamos visto anteriormente, mas também ir além, dentre os veículos que citaram Bolsonaro, o Estado de São Paulo apresenta o maior número de citações ao candidato. 


\section{Metodologia}

É necessário elucidar aspectos relacionados à coleta dos dados e a metodologia empregada neste trabalho antes de seguirmos adiante. Foram coletadas capas de nove jornais de circulação nacional e estadual durante o período compreendido entre 1 de junho e 30 de novembro de 2018. Os quatro jornais de circulação nacional são: Folha de São Paulo, Estado de São Paulo, o Globo e o Correio Braziliense; e os cinco de circulação estadual: Estado de Minas, o Tempo, Super Notícia, Metro (BH) e Hoje em Dia. Assim, a partir de quais jornais impressos farão parte de nossa base de dados, foi definido que apenas o conteúdo de suas capas se tornarão nossa fonte de dados. Os dados utilizados neste trabalho foram coletados manualmente por colaboradores do projeto de pesquisa Media Bias, que é coordenado pelo professor Felipe Nunes, do Departamento de Ciência Política da UFMG. Eles foram processados e organizados em um banco próprio, composto tanto de dados textuais das notícias quanto de características não textuais, algumas das de maior importância são: manchete, veículo, tema da notícia, nível de governo associada a notícia e personagens citados.

A escolha pela análise das capas justifica-se pelo fato de que uma análise da mídia como um todo seria virtualmente impossível e um recorte faz-se necessário. As capas e seus elementos constituintes são tratados como proxies para substituir a análise do conteúdo na íntegra. Apesar de apresentar algumas limitações, essa escolha metodológica se provou confiável para análises de aspectos mais genéricos da cobertura, como mostraram Althaus, Edy e Phalen (2001). Para o caso do presente artigo, que busca fazer uma análise descritiva dos dados coletados, a escolha das capas como unidade de análise se mostrou suficiente para os fins propostos, já que não faremos a análise de valências, mas sim, apenas lidaremos com a exposição midiática que cada candidato recebeu nas capas das mídias impressas coletadas, independentemente dessa exposição ser positiva, neutra ou negativa.

A capa de um jornal é responsável pela impressão inicial causada em seus leitores, funciona como vitrine das publicações ali contidas (FERREIRA JÚNIOR, 2003). Elas atraem e seduzem os leitores no intuito de incentivar a aquisição de um exemplar (TRAVASSOS, 2010), funcionam também como um sumário que contém de maneira resumida as principais matérias ali presentes, por isso, podem ser tratadas como uma boa amostra do que está contido dentro daquela edição. Dessa maneira, acreditamos que a representatividade das capas em relação à edição como um todo é satisfatória para o proposto nesse trabalho. 
Entretanto, a relevância das capas não se dá apenas pela sua capacidade de atrair a atenção dos leitores, mas também por ditar o tom editorial das matérias, que por sua vez, pode afetar como elas serão percebidas e lembradas pelo público, como demonstra Ecker et al. (2014). A utilização do procedimento da análise de capas para a mensuração do viés midiático em eleições não é invenção deste trabalho, existem outros esforços nesse sentido, como o de Peake (2007) e de Feres Júnior et al. (2014), é com essa literatura que buscamos estabelecer diálogo.

Neste sentido, nosso esforço se volta para a dimensão descritiva dos dados analisados bem como para o emprego do método de ARS para investigar como os veículos de circulação impressa realizaram a cobertura do evento, ou seja, se tais veículos, que por pressuposto deveriam ser imparciais na exposição midiática dos candidatos durantes as eleições, respeitaram esse princípio. Podemos, dessa forma, comparar as coberturas que cada candidato recebeu e verificar se Ihes foi concedido espaço equivalente. Esse componente do viés é compreendido pelo não cumprimento do princípio da imparcialidade na cobertura das informações veiculadas pelas mídias jornalísticas, o que já é estudado internacionalmente, visto que as mídias são um importante fator para a construção e amadurecimento das posições políticas da população, além de cumprirem papel de agentes que auxiliam no fluxo de informação, como apontam Cf. Besley e Prat (2006); Larcinese, Puglisi e Snyder (2011), dessa forma, a cobertura apresenta potencial para influenciar no resultado que o pleito apresenta.

O fundamental para nossa análise é: quem são os veículos de cada notícia e quem são os personagens citados em tais notícias, sendo que consideramos apenas as notícias classificadas com a temática de eleições ou política. É indispensável que isso fique claro, pois nossa investigação não é sobre quantidade de observações em números absolutos dentre todos os tipos de notícias veiculadas nos jornais, mas sim, apenas sobre as pertencentes à temática político-eleitoral, comparando, portanto, o quanto de cobertura cada candidato recebeu em relação a toda cobertura do processo eleitoral. Do banco que apura todas as capas, totalizando 16.969 observações, foi realizado este recorte por temas, o que resultou em um banco com apenas 4.955 observações com tema de eleições ou política, o que compreende todo o universo analisado. A partir desta delimitação foram criados gráficos para a exposição dos resultados e auxiliar na visualização dos dados, como veremos na seção a seguir. 


\section{Resultados}

Nessa seção, serão apresentados os resultados e suas respectivas análises que focam na cobertura midiática do processo eleitoral presidencial de 2018 no Brasil. Separamos a exposição dos resultados em dois momentos: o primeiro, descritivo, referente às citações dos principais candidatos à presidência nas eleições, e o segundo, focado no método de ARS em que trabalhamos de forma relacional a rede dos atores envolvidos na cobertura estudada, de forma que é possível mapear a rede de citações diretas aos personagens mencionados, bem como ter uma noção sobre o volume de citações que cada veículo de mídia estudado apresenta para cada candidato.

\section{a) Análise descritiva dos resultados}

Como apresentado, nesta seção abordamos uma análise descritiva referente às citações diretas aos principais candidatos à presidência no processo eleitoral. Apresentamos um gráfico que cobre todo o período compreendido entre 01/06/2018 e $30 / 11 / 2018$, as notícias coletadas das capas dos jornais foram agrupadas em semanas para a melhor visualização dos dados. No eixo $x$ segue a linha temporal das observações em semana a semana e no eixo y a porcentagem das citações aos candidatos à presidência. Essa escolha gráfica serve para comparar a diferente exposição que cada candidato teve ao longo do tempo em número de aparições nas capas coletadas e analisadas.

Nota-se, que no gráfico apresentado a seguir, no qual analisamos apenas os candidatos à presidência mais importantes em termos de intenção de voto e relevância histórica do partido do candidato nas eleições anteriores, a delimitação de três linhas pontilhadas no eixo $x$, essas linhas correspondem a eventos que julgamos relevantes, tanto para as eleições como para a sua cobertura, logo, essenciais para este trabalho. A primeira linha demarcada na semana de número 36, representa o evento da facada sofrida pelo então candidato Bolsonaro em um comício de campanha eleitoral em Juiz de Fora, em 06/09/2018, quando obteve 45,8\% da cobertura. É importante ressaltar que, essa foi a semana na qual identificamos uma virada na cobertura das eleições, Bolsonaro passou a ser o candidato com maior cobertura daí em diante. Até então, Lula vinha sendo o candidato mais mencionado pelas capas, mesmo após ter tido sua candidatura barrada pelo TSE (Tribunal Superior Eleitoral), em 31/08/2018. Lula chegou a alcançar expressivos $84,6 \%$ da cobertura na semana 26 , número que só seria superado por Bolsonaro depois de eleito. Haddad só seria anunci- 
ado como candidato oficial pelo PT no dia 11/09/2019, como podemos observar no gráfico, na semana 37, quando teve papel de protagonista pela primeira vez, alcançando $22,9 \%$ da exposição, enquanto Lula perdia espaço. A segunda linha demarca o primeiro turno das eleições, ocorrido em 07/10/2018, enquanto a terceira demarca o segundo turno, em 28/10/2018.

Julgamos indispensável uma observação a ser feita a respeito do período compreendido entre o primeiro e segundo turno, mais especificamente, as semanas 41 e 42. Estas semanas são importantes para a análise porque, a essa altura, havia apenas dois candidatos na disputa, o que facilita a comparação entre as porcentagens de citações nas capas dos jornais estudados. $\mathrm{Na}$ semana 41 , uma depois do primeiro turno, Bolsonaro obteve $48,4 \%$ das citações referentes às eleições, enquanto Haddad teve $30,6 \%$. Já na semana 42, uma antes do segundo turno, Bolsonaro apareceu em $58,1 \%$ das capas, enquanto Haddad apenas $34,3 \%$.

Os resultados observados a partir do gráfico abaixo nos permitem realizar algumas reflexões:

1) Apesar da desproporção de espaço concedido encontrada entre diferentes candidatos, isso não basta para cravarmos a existência de viés ou para descobrir a quem ele favorece. Porém, é certo que a questão da visibilidade é central para os estudos de viés midiático. Explicamos, apesar de uma alta visibilidade associada a uma cobertura negativa ser deletéria para a imagem dos candidatos, com certeza a baixa visibilidade também o é. Portanto, não sabemos, a partir dos dados aqui apresentados, se o candidato muito citado é prejudicado ou não, mas sabemos que aqueles que quase não aparecem tem suas chances no pleito reduzidas. Por isso, compartilhamos da opinião de que a questão da (in)visibilidade é elemento importante nos estudos de viés de mídia, como sugerem Baron (2006) e Mundim (2018).

2) Também é importante ponderar que o espaço concedido a cada candidato poderia ter relação direta à posição daquele candidato no pleito ou à importância histórica do seu partido. Ou seja, poderíamos supor que os candidatos Lula/Fernando Haddad e Geraldo Alckmin, do PT e PSDB respectivamente, seriam os mais predominantes no espaço ocupado, já que seus partidos ocupam papel de protagonismo histórico nas eleições presidenciais. Também poderíamos assumir o mesmo para Jair Bolsonaro, do PSL, que surgia nas pesquisas de intenção de voto como um dos principais candidatos na corrida. Porém, o que observamos é uma prevalência dos candidatos do PT nas semanas que antecedem a 
facada, com exceção às semanas 29 e 30, quando Alckmin foi o mais presente.

3) Essas considerações todas são colocadas em suspensão em decorrência da facada sofrida por Bolsonaro, que o coloca como - principal ator político presente nos jornais, como era de se esperar. Esse fenômeno, ao qual chamamos de efeito facada, dificulta a interpretação dos dados, uma vez que interfere drasticamente na dinâmica noticiosa dos veículos de mídia. Portanto, no período entre as semanas 36 (semana da facada) e 40 (semana do primeiro turno), atribuímos esse desiquilíbrio à enorme repercussão que o atento gerou e não a um possível viés identificado.

4) Por conta das reflexões apresentadas acima, no que tange a constatação da existência de viés, julgamos prudente centrarmos o foco da análise no período entre o primeiro e segundo turno, semanas 40 e 43. Durante esse período já não havia outros candidatos na corrida além de Bolsonaro e Haddad e a facada já tinha ocorrido havia algumas semanas. É justamente nesse período que observamos a maior disparidade entre a proporção de exposição entre os candidatos, e é quando acreditamos haver indícios mais fortes da existência de viés na cobertura realizada. Historicamente, as semanas que antecedem o segundo turno são muito importantes, pois é quando os indecisos acabam escolhendo um lado. Portanto, a constatação de exposição desproporcional em um momento tão crítico para a eleição, sem que houvesse um motivo que justificasse tal desproporção, como ocorreu nas semanas subsequentes à facada, pode ter causado um impacto no resultado do pleito, uma vez que Bolsonaro se absteve de participar dos debates e, mesmo assim, continuou em evidência nas principais mídias. 


\section{Gráfico 1. Porcentagem de citações dos principais candidatos à presidência nas eleições de 2018}

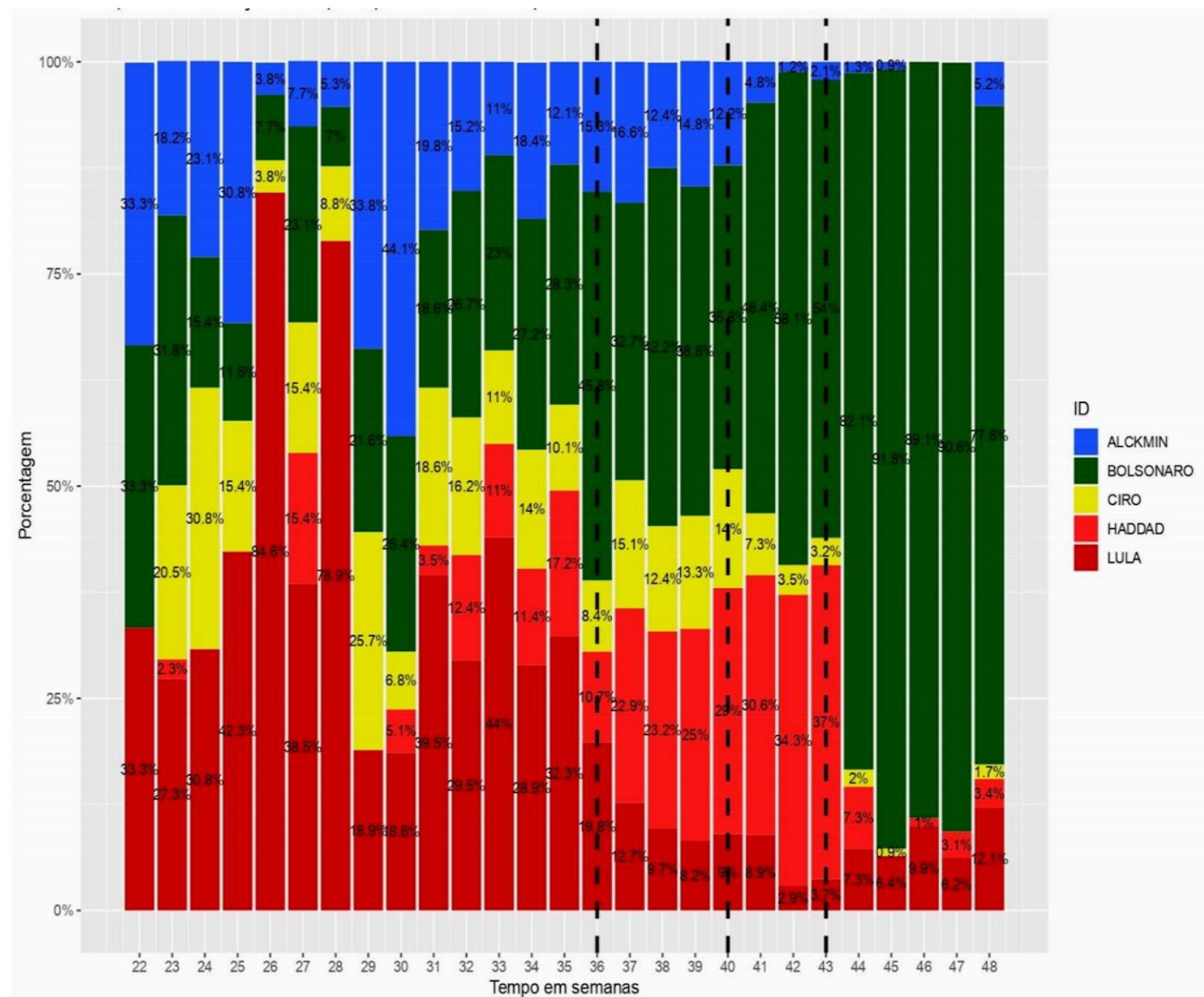

Fonte: retirado do artigo "Presença de candidatos na mídia: uma análise das eleições brasileiras de 2018" elaborado pelos integrantes ${ }^{3}$ do grupo de pesquisa Media Bias e apresentado no XIV Congresso Nacional de Ciência Política "La política en incertidumbre. Reordenamientos globales, realineamientos domésticos y la cuestión de la transparência", organizado pela Sociedad Argentina de Análisis Político e pela Universidad Nacional de San Martín, realizado entre 17 e 20 de julho de 2019.

3 * Florencia Lorenzo - Mestranda em Ciência Política pela Universidade Federal de Minas Gerais. Contato: flopi.lor@gmail.com

* Marina Amorim - Mestranda em Estatística pela Universidade Federal de Minas Gerais. Contato: mamorim@ufmg.br

* Pedro Amorim - Mestrando em Ciência Política pela Universidade Federal de Minas Gerais. Contato: pedroamorim2005@gmail.com

* Bárbara Salatiel Borges - Doutoranda em Ciência Política pela Universidade Federal de Minas Gerais. Contato: barbarasalatiel.borges@gmail.com 


\section{b Análise dos resultados a partir do método de ARS}

Nesta segunda seção apresentaremos o resultado da análise produzida a partir do método de ARS. Ela consiste em um grafo que plota a rede de atores gerada a partir dos veículos jornalísti$\cos$ e dos candidatos à presidência. Podemos, então, visualizar quais veículos jornalísticos citaram mais ou menos cada candidato nessa representação da rede "two-mode network", que é caracterizada por agregar em sua estrutura pessoas, organizações, coletivos/agregados (comunidades, estados-nação, municípios). Como argumentam Silvio Salej Higgins e Antônio Carlos Ribeiro (2018, p. 91), neste tipo de rede podem constituir os seguintes tipos de relações:

- Formas de filiação voluntária a diversos tipos de organizações

- Transações ou transferência de recursos materiais: comprar, vender, tomar emprestado de, emprestar a etc.

- Transferência de recursos não materiais: enviar ou receber informação

- Interações: ajudar a, controlar a etc.

- Movimento: físico (migrar para), social (mudar de status)

Nos interessa, porém, compreender como a rede mostrada foi construída. Ela representa os candidatos em vermelho e os veículos jornalísticos em azul, além dos laços entre eles, que é representado pelas setas. A direção para que a seta aponta indica o sentido do fluxo de informação, em outras palavras, mostra quem cita e quem é citado. Nesse caso, os jornais representam a parte emissora, enquanto os políticos citados, os receptores.

Dessa maneira conseguimos analisar o fluxo das informações na rede e sua intensidade entre cada candidato e o jornal. Quanto à intensidade da relação, pôde ser mensurada através do peso dado a cada relação entre um candidato e um jornal, ou seja, quanto mais cobertura um jornal der a um candidato mais larga será a representação da seta que parte do emissor (jornal) e segue para o receptor da interação (candidato).

A verdadeira rede consta em anexo, porém, a apresentada aqui é uma representação derivada da original. Ambas contêm as mesmas informações, porém, optamos por utilizar a rede apresen- 
tada de maneira circular para facilitar a visualização e compreensão das informações ali contidas. O grafo de redes nos mostra claramente que, Bolsonaro foi o candidato mais citado pelos veículos jornalísticos estudados, confirmando o que as proporções anteriores mostravam. Ele nos permite também, saber qual veículo teve o maior volume de citações, como por exemplo, o Estado de São Paulo foi responsável pela maior parte de todas as citações a Bolsonaro dentre os outros veículos jornalísticos. É possível observar também, que os veículos de circulação nacional têm um balanço de exposição desigual superior aos veículos estaduais, que apresentam suas representações de dos laços em espessuras similares em relação aos candidatos.

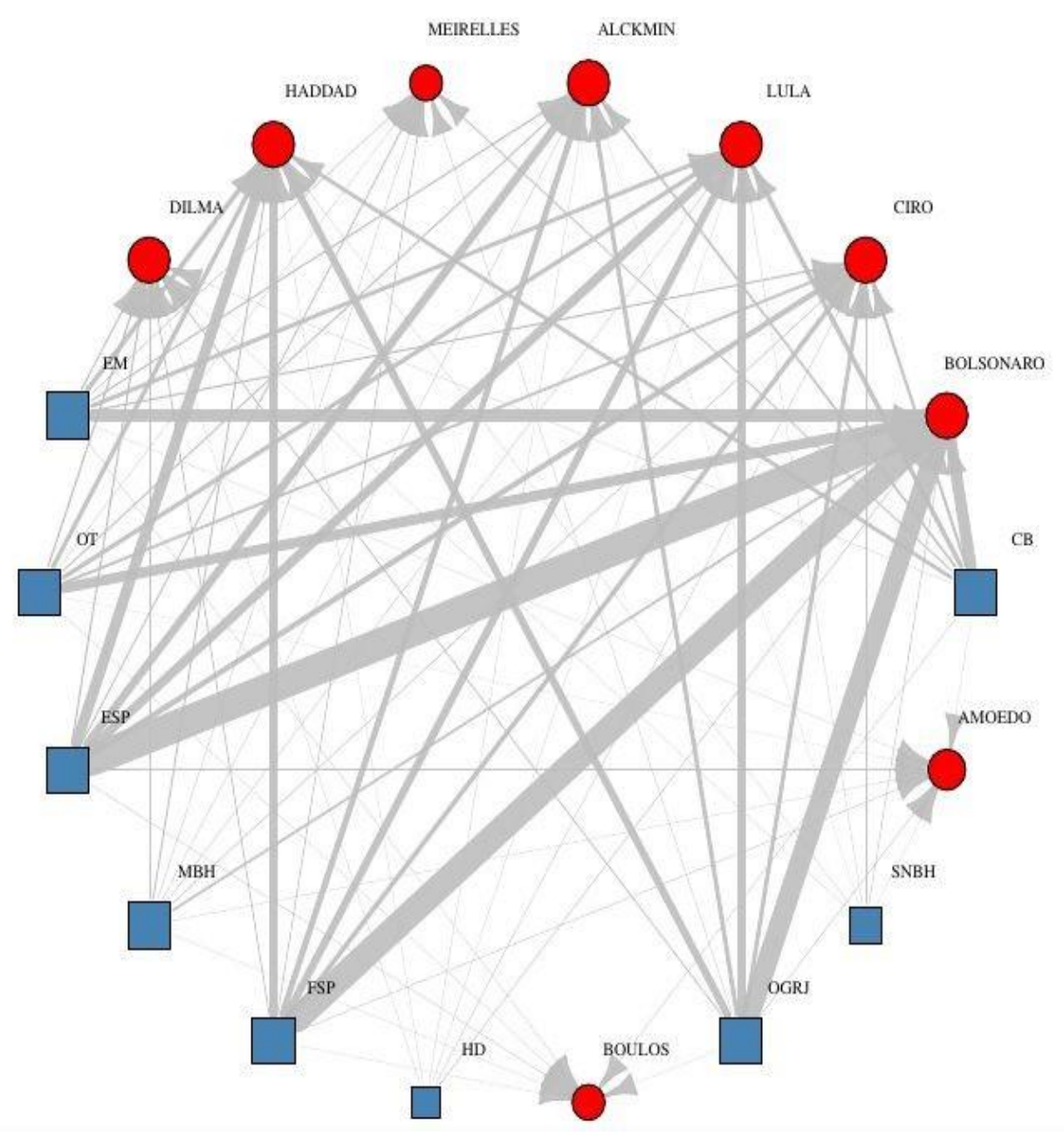

Gráfico 2. Representação circular da rede (2-mode network)

Fonte: elaboração própria. 


\begin{tabular}{|l|c|}
\hline \multicolumn{1}{|c|}{ Jornal } & Sigla \\
\hline Correio Braziliense & CB \\
\hline Estado de Minas & EM \\
\hline O Tempo & OT \\
\hline Estado de São Paulo & ESP \\
\hline Metro (BH) & MBH \\
\hline Folha de São Paulo & FSP \\
\hline Hoje em Dia & HD \\
\hline O Globo (RJ) & OGRJ \\
\hline Super notícia (BH) & SNBH \\
\hline
\end{tabular}

Tabela 1: Tabela de legendas para as siglas da dos jornais representados nas redes plotadas:

\section{Conclusão}

A partir dos dados analisados, concluímos que a cobertura jornalística realizada pelas mídias impressas estudadas dá indícios que apontam para a existência de viés, uma vez que espaço cedido é um dos elementos constituintes do viés. Em um primeiro momento, mais distante da eleição, Lula vinha recebendo bastante destaque. Supomos que isso seja em decorrência das polêmicas associadas à sua candidatura, à operação Lava-Jato e à sua expressiva popularidade, construída no período em que esteve à frente da presidência da república. Em um segundo momento, já com as eleições mais próximas, outros candidatos ganharam mais espaço, e a presença de Lula foi gradualmente caindo, até que Haddad assume o protagonismo com a oficialização de sua candidatura, quando seus números de exposição ultrapassam os de Lula pela primeira vez. Outra conclusão que pudemos chegar, foi o do papel de centralidade que a facada atribuiu a Bolsonaro, que teve a maior cobertura dentre os candidatos pela primeira vez exatamente na semana do atentado. Daí em diante, seu nome foi o mais presente até o final do segundo turno e nas semanas seguintes, o que chamamos de efeito facada.

Gostaríamos de dar destaque especial às duas semanas entre o primeiro e segundo turno por três motivos: 1) O crescimento da cobertura dedicada à Bolsonaro e o desequilíbrio identificado no espaço concedido pela mídia poderia ser justificado pelo evento 
da facada, que naturalmente, atraiu muita atenção e dominou os noticiários nas semanas subsequentes. Portanto, a argumentação a favor da existência de viés nesse período fica mais frágil por conta disso, todavia, a semana que antecedeu a eleição ocorreu seis semanas após a facada, quando a repercussão da facada já havia arrefecido; 2) A semana que antecede a votação é de suma importância para o desfecho do pleito e, justamente nessa semana, a diferença entre a cobertura dedicada a Bolsonaro e Haddad foi de $23,8 \%$ pontos percentuais, o que é uma diferença bastante expressiva; 3) Nestas duas semanas, havia apenas dois candidatos ainda na disputa, o que facilita a comparação entre eles e, por conseguinte, auxilia a análise do balanço de visibilidade dos candidatos. A partir dos dados referentes às essas semanas, concluímos que, na reta final, há fortes indícios de viés na cobertura da mídia, o que garantiu visibilidade extra para Bolsonaro, podendo assim, tê-lo favorecido.

Por fim, gostaríamos de repetir que os resultados não são totalmente conclusivos pela limitação metodológica decorrente na falta da análise de valências. Porém, mesmo assim, como a literatura citada nesse artigo sugere, estudos de viés consideram a questão da visibilidade e exposição de suma importância para a questão e é dessa forma que esse trabalho contribui com essa literatura. Sugerimos que, para a obtenção de resultados mais robustos e consistentes, estudos futuros façam um esforço complementar de trazer a análise de valências e, associada aos dados contidos neste trabalho, reflitam mais afundo sobre a existência de viés na cobertura das eleições presidenciais de 2018.

\section{Bibliografia:}

ALDÉ, Alessandra. As eleições presidenciais de 2002 nos jornais. Alceu, v. 3, n. 6, p. 93-121, 2003.

ALDÉ, A., MENDES, G., FIGUEIREDO, M. Tomando partido: imprensa e eleições presidenciais em 2006. Política e Sociedade, n. 10, 2007.

ALTHAUS, S., Edy, J., \& PHALEN, P. (2001). Using Substitutes for Full-Text

News Stories in Content Analysis: Which Text Is Best? American Journal of

Political Science, 45(3), 707-723. doi:10.2307/2669247

AVRITZER, Leonardo. O pêndulo da democracia no Brasil: Uma análise da crise 2013-2018. Novos Estudos, n. 111, p. 272-289, 2018.

AZEVEDO, Fernando. Eleições presidenciais, clivagem de classe e declínio da grande imprensa. Revista USP, n. 90, p. 84-101, 2012. 
Mídia e democracia no Brasil. Relações entre o sistema de mídia e o sistema político. OPINIÃO PÚBLICA, Campinas, vol. 12, n 1, Abril-Maio, p. 88-113, 2006.

BARON, David P. A persistente media bias. Journal of Public Economics, v. 90, p. 1-36, 2006.

BESLEY, Timothy, and Andrea Prat. "Handcuffs for the grabbing hand? Media capture and government accountability." The American Economic Review 96.3 p. 720-736, 2006.

BEZERRA, H. D.; MUNDIM, P. S.. Qual foi o papel das variáveis midiáticas na eleição presidencial de 2010? Opinião Pública, Campinas, vol. 17, n. 2, p. 452476, 2011.

BIROLI, F.; MIGUEL, L. F.; MOTA, F. F.. Mídia, eleições e pesquisas de opinião no Brasil (1989-2010): um mapeamento da presença das pesquisas na cobertura eleitoral. Compolítica, 1.1, p. 67-90, 2011.

CERVI, Emerson; MASSUCHIN, Michele. A agenda da mídia impressa brasileira durante o período eleitoral de 2010: a visibilidade dos temas políticos, sociais e de entretenimento. Observatório Journal, vol. 7, n. 1, p. 219-242, 2013.

ECKER, Ullirich. K.; LEWANDOWSKY, Stephan; CHANG, Ee. Pin; PILLAI, Rekha. The effects of subtle misinformation in news headlines. Journal of experimental psychology. Applied, v. 20(4), p.323-335, 2014.

FERES JÚNIOR, João, SASSARA, Luna de Oliveira; BARBABELA, Eduardo; MIGUEL, Lorena; CÂNDIDO, Marcia Rangel; SILVA, Thyago de Simas. A (in)clemente mídia das eleições. Insight Inteligência, n. 67, p. 46-59, 2014.

FERES JÚNIOR, João; SASSARA, Luna. O cão que nem sempre late: o Grupo Globo e a cobertura das eleições presidenciais de 2014 e 1998. Revista Compolítica, v. 6, n. 1, p. 30-63. 2016

FERREIRA JÚNIOR, José. Capas de Jornal: A primeira imagem e o espaço gráfico-visual. São Paulo: Editora Senac, 2003.

FIGUEIREDO, Rosali. Mídia e eleições: cobertura jornalística da campanha presidencial de 1994. Opinião Pública, Campinas, vol. V, n. 1, Novembro, p. $72-$ 89, 1998.

HIGGINS, Silvio Salej; ANDRADE RIBEIRO, Antonio Carlos. Análise de redes em Ciências Sociais - Brasília: Enap, p. 91, 2018.

KUCINSKI, Bernardo. A síndrome da antena parabólica: ética no jornalismo brasileiro. [S.I: s.n.], 1998.

LARCINESE, Valentino; PUGLISI, Riccardo; and SNYDER, James M. "Partisan bias in economic news: Evidence on the agenda-setting behavior of US newspapers." Journal of Public Economics 95.9 (2011): 1178-1189.

LAZEGA, E., \& Higgins, S. S. (2014). Redes sociais e estruturas relacionais. Belo Horizonte, MG: Fino Traço.

LINS DA SILVA, Carlos Eduardo. Indústria da comunicação: personagem principal das eleições presidenciais brasileiras de 1989. A: Intercom. Revista Brasileira de Comunicação, n. 62/63, 1990.

LOURENÇO, Luiz Claudio. Propaganda Negativa: ataque versus votos nas eleições presidências de 2002. Opinião Pública, Campinas, vol. 15, n. 1, p. 133158, 2009. 
LUSHER, D., Koskinen, J., \& Robins, G. (2012). Exponential random graph models for social networks: Theory, methods, and applications. Cambridge University Press.

MATOS, Carolina. Mídia e política na América Latina. Civilização Brasileira, 2013.

MCCOMBS, M. E.; SHAW, D. L. The agenda-setting function of mass media. Public opinion quarterly, 1972, 36.2: 176-187.

MIGUEL, Luis Felipe. Eleições, opinião pública e mídia: reflexões a partir das eleições brasileiras de 2002. Política e sociedade, n. 2, p. 41-66, 2003.

DOSSIÊ "MÍDIA E POLÍTICA". Apresentação. Rev. Sociol. Polít., Curitiba, 22, p. 7-12, jun. 2004.

MUNDIM, Pedro Santos. Imprensa e voto nas eleições presidenciais brasileiras de 2002 e 2006. Revista de Sociologia Eamp; Política, v.20, n.41, p. 123-47, 2012.

O viés da cobertura política da imprensa nas eleições presidenciais brasileiras de 2002, 2006 e 2010. Rev. Bras. Ciênc. Polít., Brasília, n. 25, p. 7-46, Jan. 2018.

Um modelo para medir os efeitos da cobertura da imprensa no voto: teste nas eleições de 2002 e 2006. Opinião Pública, Campinas, vol. 16, n 2, p.394-425, 2010.

NUNES, Felipe; RANULFO MELO, Carlos. Impeachment, political crisis and democracy in Brazil. Revista de Ciência Política, vol. 37, no 2, 2017.

PEAKE. Jeffrey S. Presidents and Front-page News: How America's Newspapers Cover the Bush Administration. The Harvard International Journal of Press/Politics, v.12, n.4, p.52-70, 2007.

RUBIM, A. A. C.; AZEVEDO, F. A., Mídia e política no Brasil. Textos e agenda de pesquisa. Lua Nova, São Paulo, n. 43, p. 189-216, 1998.

R Core Team (2017). R: A language and environment for statistical computing. R Foundation for Statistical Computing, Vienna, Austria. URL: https://www.Rproject.org/

https://kateto.net/network-visualization

http://neylsoncrepalde.github.io/ 
Uma análise de rede das mídias tradicionais e a cobertura das eleições

Apêndice 1 - Representação da rede original (2-mode network) a partir da qual foi criada a rede circular presente no gráfico 4.

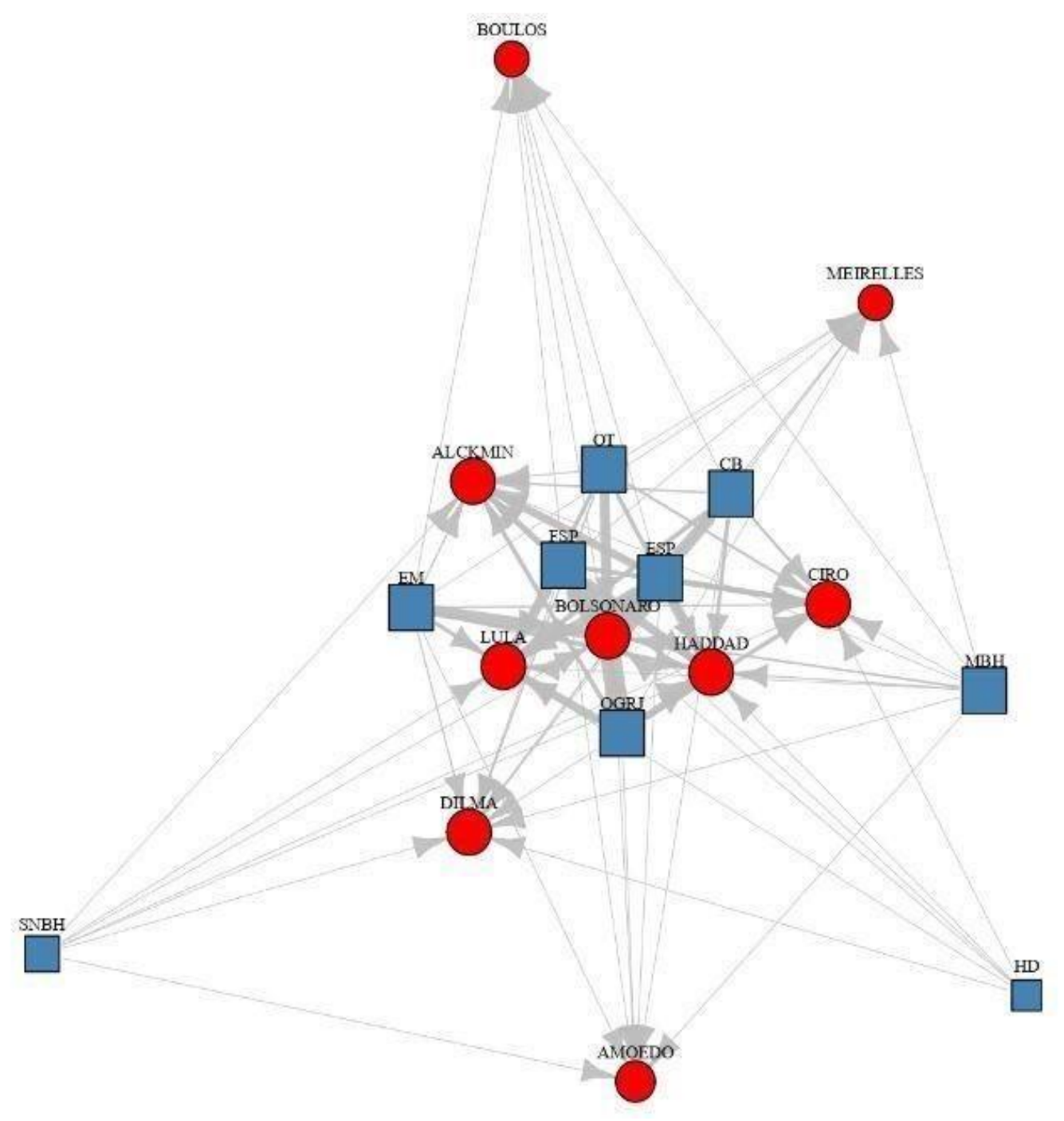

Fonte: elaboração própria. 